\title{
The Role of Social Communications in Private Medical Clinic Brand Management During the Covid-19 Pandemic
}

\author{
Natalia Izakova*, Tatyana Solosichenco, Ivan Vozmilov, Olga Popova \\ Ural State University of Economics, Ekaterinburg, Russia \\ *Corresponding author. Email: izakovan@gmail.com
}

\begin{abstract}
Assessing the effectiveness of branding is an important task for business, as it allows you to identify the key tools for increasing the company's competitiveness in the market. In times of social distance and limited contacts, the role of social communications for the interaction of a brand with its consumers increases. The article analyzes various approaches to assessing the effectiveness of brand management. A correlation-regression model for assessing the effectiveness of brand management of private medical clinics is proposed. The value of the market share was chosen as an indicator of branding efficiency, as an indicator reflecting the most important results of the company's activities, the level of dominance of the enterprise in the market. As factors influencing the effectiveness of brand management, indicators of the level of brand awareness were selected: "Top-of-mind", "Spontaneous awareness", "Induced awareness". The hypothesis that brand awareness of a medical clinic affects the size of a company's share in the private medical services market has been tested and confirmed. Based on the results of the study, recommendations were formulated on the choice of social communications that have the greatest impact on the formation of awareness and the effectiveness of brand management in the context of the COVID-19 pandemic.
\end{abstract}

Keywords: brand management, social communication, brand recognition, market healthcare services, COVID-19

\section{INTRODUCTION}

In the current context of the COVID-19 pandemic, commercial medical clinics could be hit hard when faced with declining brand awareness. The pandemic has affected all sectors of the economy both in the world and in Russia, not bypassing the attention of the commercial medicine market. According to a study of the commercial medicine market in Russia conducted by Ernst \& Young - Assessment and Consulting Services, at the end of 2020 , the commercial medicine market amounted to about 738 - 740 billion rubles in the healthcare system of the Russian Federation. This indicator corresponds to the level of 2012. The growth rate showed negative dynamics, decreasing by $14 \%$ in relation to the previous year [1]. During this period, it is very important to attract and retain the attention of existing and potential clients and maintain the status of a well-known and reliable clinic that you can entrust your health to. Therefore, the leading medical centers in the region pay special attention to increasing brand awareness and promoting it in the medical services market.

The use of social media to promote, disseminate and discuss medical knowledge, initiatives, projects, research, news and other activities between people today has become one of the most effective means of communication, more useful than traditional methods. And in this regard, social communications not only allow users to find out what people from their circle of communication are doing, but they also facilitate the automatic selection of the necessary information, reputation management. The adaptation of companies to new economic conditions presupposes new approaches to communicating with consumers. Brands should try to make life easier for people and offer them preferential terms of cooperation.

Increased competition in the paid medical services market is associated not only with a decrease in the number of budgetary medical institutions, but also with several private clinics, as well as commercial units in 
departmental medical institutions, and the emergence of small clinics, laboratories, and medical offices. Consumers have become more aware of the possibilities of medical care and, when choosing a medical organization, more and more attention is paid to the availability and reliability of information about what kind of care they can receive, which speaks of the importance of recognizing a medical brand among the population. Private medical clinics need to attract more clients to cover costs and profit, and therefore it is necessary to look for ways to increase awareness of the brand and the services that clinics provide.

Identification and systematization of factors affecting brand recognition and effectiveness is an urgent task for participants in the private medical services market. The relevance of the authors' research is dictated by the need to choose social communications that have the greatest impact on the formation of brand awareness and the effectiveness of brand management in the difficult environmental conditions that have arisen under the influence of the COVID-19 pandemic.

The purpose of this study is to develop and test a model for assessing the effectiveness of brand management in private medical clinics. The object of the study was private medical clinics operating in the market of Ekaterinburg.

Modern research on the influence of brands on the companies' performance is differentiated in various areas and industries. Several studies D. R. Lehmann, K. L. Keller, R.A. Kerin, T.J. Madden is devoted to the study of the influence of the brand on the shareholder value of the company [2-4]. The key characteristic of brand value that distinguishes it from competitors, most authors consider the position of the brand, which is understood as the main characteristics of a product or service, broadcast by the company to target consumers [5]. According to P. Sultan and Ho Yin Wong branding does not only provide increased attention and mentions in the media, but also brings economic and social results [6]. A. S. Ehrenberg, M. D. Uncles. G. J. Goodhardt say that brand performance is a relative measure of brand success, which must be compared with the success of other brands in the market [7].

In order to assess marketing costs, the researchers suggest using various financial and market indicators of brand performance, for example, sales growth, market share of the company, and in financial indicators: average annual growth rates, sales volume, market share, gross profit, return on investment and return on assets [8-10]. Financial indicators turned out to be insufficient to understand the effectiveness of branding and marketing productivity, in connection with which a number of authors have proposed to expand the use of non-financial indicators [11]. H, Tsai and LHN Fong also observed that metrics such as brand equity, brand awareness and loyalty have an impact on the financial performance of companies [12].

Based on the broad understanding of the brand as an economic category, it should be noted that the effectiveness of a brand can be associated not only with the economic achievements of the company and an increase in market share, but also with purchasing behavior, brand awareness, perception, the formation of loyalty and the establishment of long-term relationships with a regular consumer. S. Luxton, S. H. Han et al. Suggest that a model for assessing brand performance should be based on consumer behavior, brand awareness and perception [10, 13]. Analyzing the factors influencing the recognition and perception of the brand by consumers, modern scientists emphasize the significant role of digital communication technologies [15-18].

It can be concluded that a generally accepted methodology that would embody an integrated approach and represent a system of metrics capable of comprehensively assessing the effectiveness of work on a brand has not yet been developed. The relevance of the search for a methodological approach that would make it possible to link both market indicators of brand management efficiency and indicators of brand awareness by the consumer, formed with the help of social communications, remains relevant. The model proposed by the authors can be applied not only to the medical services market, but also to other B2C and B2B markets.

\section{MATERIALS AND METHODS}

To assess the level of brand awareness, the authors propose to measure it in three dimensions:

1. The "Top-of-mind" indicator is the percentage of respondents who first of all remembered a particular brand when answering the question: "What brands of goods or services of category X do you know?". If the top-of-mind indicator approaches $15-20 \%$, then we can say that the company's brand has penetrated deeply into the consciousness of consumers, which makes the company attractive to many potential buyers.

2. The indicator "Spontaneous awareness", or recognition without prompting - the rating of brands that the respondents remembered on their own, without prompting. A brand can be considered recognizable if the organization is in the first or second place in the ranking.

3. Indicator "Induced awareness" or prompted recognition - the percentage of respondents who chose a particular brand from the list presented to it.

The authors proposed a correlation-regression model of the dependence of the company's market share on the level of brand awareness by the consumer: 


$$
D_{i}=\alpha+\beta_{1} \times X_{1 i}+\beta_{2} \times X_{2 i}+\beta_{3} \times X_{3 i}+\varepsilon,
$$

where Di is the company's market share, \%; X1i Top-of-mind indicator, \%; X2i - indicator of spontaneous awareness, $\%$; $\mathrm{X} 3 \mathrm{i}$ is the indicator of induced awareness, $\%$; $\alpha$ is a constant; $\beta 1,2,3$ regression coefficients; $\varepsilon$ - residuals.

To assess the level of brand awareness and select the most significant communication channels for consumers, a survey is being conducted. The respondents are asked to name, without prompting, three brands they know in the studied market, and also to choose from the offered brands that they know. The collected information is systematized for further construction of the correlation-regression model. The value of the market share was chosen as a financial indicator of branding efficiency, as an indicator reflecting the most important results of the company's activities, the level of dominance of the enterprise in the market. Correlation analysis is used to determine if there is a relationship between brand revenue and market share and brand awareness metrics. The application of the regression model allows predicting the level of market share in accordance with the change in the level of brand awareness by the consumer.

The purpose of building a correlation-regression model is to test the hypothesis that brand awareness of a medical clinic affects the size of a company's share in the private medical services market.

\section{RESULTS AND DISCUSSION}

The methodology was tested on the example of 24 private medical clinics operating in the city of Ekaterinburg. The study was conducted by the authors using the Statistical Package for the Social Science (SPSS) software. The sources of information are the results of a survey of residents of Ekaterinburg, conducted by the authors, as well as the SPARK reference and information system. To assess the impact of branding on the financial performance of private medical clinics, the authors conducted a survey of residents of Ekaterinburg in March-April 2021. The sample consisted of 447 respondents. With the help of an online survey on the Internet through Google Docs, 300 respondents were interviewed, and 147 respondents took part in a personal survey on the streets of all administrative districts of the city of Ekaterinburg. For the study, the authors selected clinics that provide multidisciplinary medical services in the market of Ekaterinburg. The final database includes clinics that respondents named at least once. The values of the indicators revenue and market share were obtained by the authors from the SPARK reference and information system. The values of the indicators "Top-of-mind", spontaneous awareness, induced awareness was calculated by the authors based on the results of a survey.

The largest non-governmental medical institutions are UMMC-Zdorovye, City Hospital No. 41, Doctor Plus, Harmony, Chance, Paracelsus, Zdorovye 365, SMT-Clinic. In total, they have 41 points, 14 of which are Doctor Plus. Their revenue in 2020 totaled more than 4.5 billion rubles, which is $12.5 \%$ higher than the results of 2019.

Correlation analysis showed a statistically significant correlation between the market share of private medical clinics and brand awareness (Table 1).

Table 1. Correlations between market share and brand uptake of private medical clinics

\begin{tabular}{|l|l|l|}
\hline Brand awareness metrics, \% & \multicolumn{2}{|l|}{ Market Share, \% } \\
\cline { 2 - 3 } & R-Pearson & Signif., $\mathrm{p}$ \\
\hline Top-of-mind, X1, & 0,980 & 0,000 \\
\hline Spontaneous awareness, X2 & 0,611 & 0,002 \\
\hline Induced awareness, X3 & 0,604 & 0,002 \\
\hline
\end{tabular}

Based on the values of the Pearson correlation coefficient, we conclude that there is a strong direct relationship between the market share of private medical clinics and the brand awareness indicator "Top-of-mind" - 0.980. Spontaneous and Awareness Metrics also directly correlate with market share, but the strength of this correlation has already been diminished. The value of the p-level of significance for each indicator is less than 0.05 , which indicates the statistical reliability of the revealed dependence. The regression analysis revealed the effect of multicollinearity between the indicators of spontaneous (X2) and induced (X3) awareness (Pearson's correlation coefficient 0.923), as well as a large error value of the coefficient of the induced awareness indicator (0.698), and therefore excluded this indicator from the final model for private medical clinics.

A regression model was built for the dependence of the share of clinics in the private medical services market on brand awareness:

$$
D_{i}=-1,127+1,27 \times X_{1 i}+1,49 \times X_{2 i}+\varepsilon
$$

where Di is the company's share in the private medical services market, \%; X1i - Top-of-mind indicator for private medical clinics, \%; X2i - indicator of spontaneous awareness of private medical clinics, $\%$.

The data on the summary for regression analysis indicate the statistical significance of the constructed model: the R-squared value is 0.978 , the significance index is $p=0.000$, which is significantly lower than the acceptable value of 0.05 . We also checked the adequacy of the regression coefficients using the t-test. The factor 
is considered significant if the t-criterion is higher than 2.00 in absolute value (more precisely, higher than 1.96), which corresponds to the significance level of 0.05 . In our case, all the coefficients of the regression model are statistically significant. An induced recognition score with a t-score below 1.96 was previously excluded from the model. The values of the regression coefficients show the degree of influence of each indicator on the value of the market share of private medical clinics. The coefficient of the spontaneous recognition indicator is slightly higher (1.49) than that of the Top-of-mind indicator (1.27). The constructed model confirms the hypothesis that brand awareness of a medical clinic has a positive effect on the size of a company's share in the private medical services market. Using the values of the recognition indicators, the regression model makes it possible to predict the dynamics of the company's market share.

Analysis of the respondents' answers to the question: "From what sources do you get information about private medical clinics?" Showed that the majority use the search engines Yandex and Google - 71\%, 43\% of respondents called the clinic's website an important channel for obtaining information, and pages medical institutions in social networks, they were chosen by $36 \%$ of respondents. $39 \%$ of respondents continue to trust information from offline channels: advertising, including outdoor advertising, television, radio, and print media. $18 \%$ of respondents answered that they receive information about clinics from friends, acquaintances, relatives.

As a result of the research, the authors have developed recommendations for the choice of social communications that have the greatest impact on the formation of brand awareness and the effectiveness of brand management in the context of the coronavirus pandemic:

- informing customers on the website and in social networks about the rules of behavior and hygiene in a pandemic.

- the use of services for organizing video calls to the clinic for consultation with a doctor, the introduction of telemedicine consultations.

- installation of an advanced system of smart bots to the dispatch network and an online operator for faster responses to patients.

- an increase in using the "Instagram" social medium, the development of a plan for thematic videos, consultations of specialists. This will help to significantly increase the recognition of the clinic not only in Ekaterinburg, but also in the country. QR codes of the official social network channel can be placed on the website, in other social networks, in the clinic itself. It can be entertaining, educational, or mixed content aimed at both younger and older audiences.
- conducting surveys for potential patients in social media.

- demonstrating the capabilities of unique medical equipment in the social media.

- maintaining relationships with current and future customers: monitoring customer reviews, in order to eliminate the shortcomings of the services provided.

- the development of personalized medicine as the basis for the interaction of a doctor with a patient, which will make treatment more targeted and accurate.

These solutions will not only increase the brand awareness of the medical clinic, but also create informational reasons for word of mouth, the transmission of information by the clinic's clients to their relatives, friends, colleagues, acquaintances.

\section{CONCLUSION}

The study made it possible to establish that brand awareness in the private healthcare market has a significant impact on the market share controlled by the clinic. When choosing paid medical services for a consumer, it is important how well-known and recognizable the clinic is in the region. The object of the research was 24 private medical clinics operating in the market of Yekaterinburg. It has been revealed that private medical clinics can achieve better results in the context of the COVID-19 pandemic through the development and implementation of a social communications program aimed at increasing brand awareness. The use of the correlation-regression model for assessing the effectiveness of brand management, proposed by the authors, should be based on reliable marketing information, which makes it possible to consider changes in the estimates of brand awareness by consumers, which requires regular marketing research. To obtain more complete and relevant information, it is planned to continue the study and study the influence of indicators of the level of brand loyalty and perceived quality of services on the financial results of the activities of private medical clinics.

\section{REFERENCES}

[1] Market research of commercial medicine in Russia.

[2] D. R. Lehmann, K. L.Keller, J. U. Farley, The Structure of Survey-Based Brand Metrics. Journal of International Marketing, 16(4) (2008) pp.29-56.

[3] R.A. Kerin., R. Sethuraman, Exploring the Brand Value-Shareholder Value Nexus for Consumer Goods Companies, Journal of the Academy of Marketing Science, 26(4) (1998) pp. 260-273.

[4] T.J. Madden. F. Fehle, S. Fournier, Brands Matter: An Empirical Demonstration of the Creation of Shareholder Value Through Branding. Journal of 
the Academy of Marketing Science, 34(2) (2006) pp. 224-235.

[5] L. M. Kapustina, E. A. Zhadko, Brand management based on consumer perceptions of a University, The Manager, 4(10) (2019) pp. 98-109.

[6] P. Sultan, Ho Yin. Wong. How service quality affects university brand performance, university brand image and behavioral intention: The mediating effects of satisfaction and trust and moderating roles of gender and study mode. Journal of Brand Management, 26(3) (2019) pp. 332-347.

[7] A. S. Ehrenberg, M. D. Uncles. G. J. Goodhardt, understanding brand performance measures: using Dirichlet benchmarks. Journal of Business Research, 57(12) (2004) pp.1307-1325.

[8] D. A. Coleman, L. de Chernatony, G. Christodoulides, B2B service brand identity and brand performance: an empirical investigation in the UK's B2B IT services sector. European Journal of Marketing, 49(7/8) (2015) pp.1139-1162.

[9] G. Christodoulides, L. De Chernatony, Consumerbased brand equity conceptualization and measurement: A literature review. International Journal of Research in Marketing, 52(1) (2010) pp. 43-66.

[10] S. Luxton, M. Reid, F. Mavondo, Integrated marketing communication capability and brand performance. Journal of Advertising, 44(1) (2015) pp. 37-46.

[11] R.T. Rust, T. Ambler, G.S. Carpenter, V. Kumar, R.K. Srivastava, Measuring marketing productivity: current knowledge and future directions. Journal of Marketing, 68(4) (2004) pp. 76-89.

[12] H. Tsai, LHN Fong, Casino-induced satisfaction of needs and casino customer loyalty: the moderating role of subjective norms and perceived gaming value. Journal of Travel \& Tourism Marketing. $n$. 38(5), pp. 21478-49021.

[13] S. H, Han, B. Nguyen, T. J. Lee, Consumer-based chain restaurant brand equity, brand reputation, and brand trust. International Journal of Hospitality Management, 50 (2015) pp. 84-93.

[14] S. Y Lam, V.Shankar, Asymmetries in the effects of drivers of brand loyalty between early and late adopters and across technology generations. Journal of Interactive Marketing, 28(1) (2014) pp. 26-42.
[15] . Kusa, A. Zauskova, L. Cabyova, Effect of marketing communication on consumer preferences and purchasing decisions. Ad Alta: Journal of Interdisciplinary Research, 10(1) (2020) pp. 150-155.

[16] E.M. Oancea Olimpia, The Influence of the Integrated Marketing Communication on the Consumer Buying Behaviour, 2020. https://www.sciencedirect.com/science/article/pii/S 2212567115004463

[17] F. Almeida, J. Almeida, M. Mota, Perceptions and Trends of Booking Online Payments in Tourism, Journal of Tourism and Services, 10(18) (2019) pp. 1-15. DOI: https://doi.org/10.29036/jots.v10i18.39

[18] K. Ajaz Khan, G. Çera, V. Nétek, Perception of the Selected Business Environment Aspects by Service Firms. Journal of Tourism and Services, 10(19) 2019. pp. 111-127. DOI: https://doi.org/10.29036/jots.v10i19.115. 